been identified that are associated with hyperlipoproteinemia (a) in each of the analysed groups.

Disclosure of Interest: None declared

DOI: 10.1136/annrheumdis-2018-eular.4993

\section{FRI0188 FACTORS ASSOCIATED WITH PATIENT-PHYSICIAN DISCORDANCE IN GLOBAL ASSESSMENT IN PATIENTS WITH AXIAL SPONDYLOARTHRITIS: AN ASIAN PERSPECTIVE}

C. Wang ${ }^{1}$, W. Fong ${ }^{1}$, Y.H. Kwan ${ }^{2}$, J.K. Phang ${ }^{1}$, N.L. Lui' ${ }^{1}$, Y.Y. Leung ${ }^{1}$, J. Thumboo' ${ }^{1}$, P. Cheung ${ }^{3}$. 'Department of Rheumatology and Immunology, Singapore General Hospital; ${ }^{2}$ Program in Health Services and Systems Research, Duke-NUS Medical School; ${ }^{3}$ Department of Rheumatology, Allergy and Immunology, National University Hospital Singapore, Singapore, Singapore

Background: Shared decision making between patients and physicians is important in the management of patients with axial spondyloarthritis. However patient's perspective on disease activity is not always similar to physician's perspective. ${ }^{1}$ There are limited studies on patient-physician discordance, none of which is based on Asian population.

Objectives: To identify the factors associated with patient-physician discordance in patients with axial spondyloarthritis (axSpA) in an Asian population.

Methods: A cross-sectional study was conducted in 2 tertiary referral centres in Singapore. Patients who fulfilled ASAS 2009 criteria for axial spondyloarthritis (axSpA) were recruited. Sociodemographic, clinical, laboratory and patient reported outcomes (PROs) data were collected during study visits from 2014 to 2015. We performed univariate and multivariate logistics regression analysis to evaluate the factors associated with patient-physician discordance, which we defined as the absolute difference $>20 \mathrm{~mm}$ between Patient Global Assessment (PGA) and Physician Global Assessment (PhGA).

Abstract FRI0188 - Table 1. Multivariate logistic regression analysis of patient-physician (PGA-PhGA) discordance with different variables.

\begin{tabular}{lcc}
\hline Characteristics & PGA-PhGA & \\
\hline & OR $(95 \% \mathrm{Cl})$ & p value \\
Current age & $1.00(0.98-1.02)$ & 0.69 \\
Education $^{\mathrm{a}}$ & $0.35(0.12-0.98)$ & 0.04 \\
If post-secondary (6 years) $_{\text {Pain score }}$ & \\
BASFI & $1.03(1.01-1.05)$ & $<0.01$ \\
ASDAS CRP & $1.08(0.94-1.25)$ & 0.23 \\
Current Biologics use & $0.82(0.59-1.13)$ & 0.23 \\
\hline
\end{tabular}

Abbreviations: ASDAS CRP: Ankylosing Spondylitis Disease Activity Score C-reactive protein; BASFI: Bath Ankylosing Spondylitis Functional Index

Results: 298 axSpA patients were included: $82 \%$ male, $81 \%$ Chinese, median age of 40 (range:20-78) years, median disease duration of 9 (range:0.1-48) years. $80 \%$ were on non-steroidal anti-inflammatory drugs and $23 \%$ were on biologics. In univariate logistic regression analysis, current age (OR:1.01, $p=0.09$ ), post-secondary education level (OR:0.34, $p=0.02)$, pain score (OR:1.03, $p<0.01)$, Bath Ankylosing Spondylitis Functional Index (BASFI) (OR:1.26, p<0.01), Ankylosing Spondylitis Disease Activity Score C-reactive protein (ASDAS-CRP) (OR:1.39, $p<0.01$ ) and current use of biologics (OR:1.80, $\mathrm{p}=0.05)$ were associated with patient-physician discordance. In multivariate logistic regression analysis, pain score (OR:1.03, p<0.01), post-secondary education level (OR:0.35, $\mathrm{p}=0.04)$ and current biologics use (OR:2.63, $\mathrm{p}<0.01)$ were associated with patient-physician discordance.

\section{REFERENCE:}

a with reference to pre-secondary

Conclusions: Higher pain score, lower education level and current biologics use were associated with greater patient-physician discordance. These factors should be taken into account during shared decision making.

\section{REFERENCE:}

[1] Desthieux C, Molto A, Granger B, Saraux A, Fautrel B, Gossec L. Patientphysician discordance in global assessment in early spondyloarthritis and its change over time: the DESIR cohort. Annals of the Rheumatic Diseases 2016;75(9):1661-6.

Disclosure of Interest: None declared DOI: 10.1136/annrheumdis-2018-eular.1610

\section{FRI0189 PERIPHERAL MANIFESTATIONS IN SPONDYLOARTHRITIS: IMPACT ON PATIENT- REPORTED OUTCOMES (PROS) AND TREATMENT. DATA FROM ASAS-COMOSPA}

C. López-Medina ${ }^{1,2}$, A. Moltó ${ }^{1,3}$, M. Dougados ${ }^{1,3} .{ }^{1}$ Rheumatology, Cochin Hospital, Paris, France; ${ }^{2}$ Rheumatology, Hospital Universitario Reina Sofía/IMIBIC/ Universidad de Córdoba, Córdoba, Spain; ${ }^{3}$ Inserm (U1153), clinical epidemiology and biostatistics., PRES Sorbonne Paris-Cité, Paris, France

Background: Peripheral manifestations (arthritis, enthesitis and dactylitis) are frequent in patients with Spondyloarthritis $(\mathrm{SpA})^{1}$. However, little is known regarding the impact of these manifestations on patients' disease perception and treatments.

Objectives: To evaluate the impact of the presence of peripheral manifestations on patient-reported outcomes (PROs) and treatment.

Methods: Data from the ASAS-COMOSPA study were analysed. Patients who reported peripheral arthritis were divided into three groups: current, past history and no history. The impact of the presence of peripheral arthritis on VAS-G (Global Visual Analogue Scale), BASDAI (Bath Ankylosing Spondylitis Activity Index), BASFI (Bath Ankylosing Spondylitis Functional Index), work and activity impairment was evaluated through the use of the ANOVA one factor test. Finally, NSAIDs, corticosteroids and DMARDs intake were compared among patients with and without peripheral articular involvement.

A similar statistical analysis was performed for enthesitis and dactylitis.

Results: Among the 3984 patients included in the ASAS-COMOSPA study, 1333 (33.5\%), $718(18 \%)$ and 1933 (48.5\%) patients had current, past history and no history of peripheral arthritis, respectively. Patients with current peripheral arthritis showed higher levels in VAS-G, BASDAI, BASFI, as well as in work and activity impairment, in comparison to the other two groups, being these differences statis tically significant $(p<0.01)$. Patients with peripheral articular involvement at the time of the visit showed higher mean scores in all questions of the BASDAI questionnaire, in contrast to those with past history and/or no history $(p<0.001)$. Impact on treatment is shown in table 1 .

Regarding enthesitis, 642 (16.1\%), 864 (21.7\%) and 2478 (62.2\%) patients had current, past history and no history of enthesitis, respectively. Patients with current enthesitis showed significant higher levels in all PROs against the other two groups of patients $(p<0.05)$, as well as higher scores in all the BASDAl questions $(p<0.001)$. Finally, 171 (4.3\%), 447 (11.2\%) and 3366 (84.5\%) patients had current, past history and no history of dacylitis, respectively. The same results as the other two peripheral manifestations were obtained regarding impact on PROs and BASDAI questions.

Conclusions: The presence of any of the three peripheral manifestations at the time of the visit was associated to higher scores in all PROs. Patients with peripheral involvement showed greater use of NSAIDs, corticosteroids and DMARDs than those without peripheral manifestations.

\section{REFERENCE:}

[1] Dougados M, d'Agostino MA, Banessiano J, et al. Joint Bone Spine 2011 Dec;78(6):589-603. doi:10.1016/j.jbspin.2011.01.013

Disclosure of Interest: None declared

DOI: 10.1136/annrheumdis-2018-eular.5331

Abstract FRI0189 - Table 1

\begin{tabular}{|c|c|c|c|c|c|c|c|c|c|}
\hline \multirow[t]{2}{*}{ Patients using: } & \multicolumn{3}{|c|}{ Current or past history of arthritis } & \multicolumn{3}{|c|}{ Current or past history of enthesitis } & \multicolumn{3}{|c|}{ Current or past history of dactylitis } \\
\hline & $\begin{array}{l}\text { Yes }=2051 \\
\text { n (\%) }\end{array}$ & $\begin{array}{c}\text { No }=328 \\
\text { n (\%) }\end{array}$ & p-value & $\begin{array}{c}\text { Yes }=1506 \\
n(\%)\end{array}$ & $\begin{array}{c}\text { No }=2478 \\
\text { n (\%) }\end{array}$ & p-value & $\begin{array}{c}\text { Yes }=618 \\
n(\%)\end{array}$ & $\begin{array}{c}\text { No }=3366 \\
n(\%)\end{array}$ & $\mathrm{p}$-value \\
\hline NSAIDs & 1858 (90.6) & $1690(87.4)$ & 0.001 & $1402(93.1)$ & $2146(86.6)$ & $<0.001$ & $568(91.9)$ & 2980 (88.5) & 0.013 \\
\hline csDMARDs & $1581(77.1)$ & $790(40.9)$ & $<0.001$ & $1062(70.5)$ & $1309(52.8)$ & $<0.001$ & $492(79.6)$ & $1879(55.8)$ & $<0.001$ \\
\hline bDMARDs & $987(48.1)$ & $755(39.1)$ & $<0.001$ & $750(49.8)$ & $992(40.0)$ & $<0.001$ & $330(53.4)$ & $1412(41.9)$ & $<0.001$ \\
\hline Corticosteroids & $1048(51.1)$ & $475(24.6)$ & $<0.001$ & $738(49.0)$ & $785(31.7)$ & $<0.001$ & $330(53.4)$ & $1193(35.4)$ & $<0.001$ \\
\hline
\end{tabular}

